\title{
Ocorrência de Sarcocystis (Lankester, 1882) na musculatura cardíaca de bovinos comercializados em feiras livres do município de São Lourenço da Mata - Pernambuco - Brasil
}

\author{
Occurrence of Sarcocystis (Lankester, 1882) in bovine \\ heart muscle from city of São Lourenço da Mata - \\ Pernambuco - Brasil
}

\author{
Vania Lucia de Assis Santana, ${ }^{\star}$ Leucio Câmara Alves, ${ }^{\star \star}$ Marta Pedrosa Souto-Maior, ${ }^{\star \star \star}$

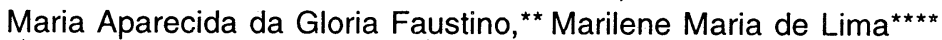

\begin{abstract}
Resumo
Os protozoários do gênero Sarcocystis infectam mamíferos domésticos, incluindo o homem, desenvolvendo-se na musculatura esquelética, sendo transmitido através da ingestão de carne crua ou mal cozida. Objetivou-se neste trabalho verificar a ocorrência de Sarcocystis spp. em músculo cardíaco de bovino. Amostras de coração foram obtidas em feiras livres do município de São Lourenço da Mata - PE, Brasil e encaminhadas ao Laboratório de Patologia Animal do DMV/UFRPE, já submetidas a cortes transversos fixados em solução de Formol a 10\%, procedendo-se à diafanização, inclusão em parafina e coloração pela hematoxilina - eosina. Todas as amostras apresentaram-se altamente infectadas por Sarcocystis spp.
\end{abstract}

Palavras-chave: Sarcocystis, bovinos, musculatura cardíaca.

\begin{abstract}
Sarcosporidiosis is an infection caused by Sarcocystis a protozoan parasite of domestic mammals and man. This transmission occurs by eating raw or underdone infected meat. The aim of this work was to detect Sarcocystis in bovine heart muscle from city of São Lourenço da Mata - PE, Brazil. The frequency of $100 \%$ was detected in the examined samples. All available hearts showed highly infected.
\end{abstract}

Keywords: Sarcocystis, bovine, heart muscle.

\section{Introdução}

Sarcocystis são protozoários parasitas dos mamíferos domésticos, aves e répteis, além dos animais silvestres, destacando-se os bovinos como principal fonte de infecção para o homem. Os bovinos são hospedeiros intermediários de $S$. cruzi, S. hominis e $S$. hirsuta, tendo como hospedeiros definitivos caninos, felinos e primatas, respectivamente. $O$ homem é hospedeiro definitivo de outras espécies de Sarcocystis, mas foi evidenciado, segundo Ferreira (1969a), como hospedeiro intermediário de $S$. lindemanni, desconhecendo-se seu hospedeiro definitivo.

A sarcocistose é uma infecção causada pela invasão do endotélio e músculos por protozoários coccídeos do gênero Sarcocystis, de ampla distribuição mundial. A prevalência de Sarcocystis em bovinos naturalmente infectados tem sido investigada em muitos países, incluindo Japão, e estes relatos têm indicado alta taxa de morbidade (Ono e Ohsumi, 1999).
É encontrado comumente na forma cística observada em cortes histológicos do coração e musculatura esquelética (Fraser, 1991; Oryan et al., 1996; Hodgson e Parish, 1993). Os sarcocistos são na maioria microscópicos (Fraser, 1991; Oryan et al., 1996 e Soulsby, 1987), porém, algumas espécies podem crescer tornando-se visíveis a olho nu, causando grandes prejuízos na indústria cárnea devido à rejeição de carcaças para consumo humano (Oryan et al., 1996).

Os cistos são delimitados por uma cápsula conjuntiva, espessa, com trabéculas fibrosas no interior (Ferreira, 1969 ). A região periférica contém formas globulares (metrócitos) que, por endodiogenia, dão lugar a duas células filhas, que se multiplicam produzindo bradizoítos de forma plana, constituindo-se na forma infectante para o hospedeiro definitivo. Estes, possuem numerosos micronemas e ultraestruturalmente se assemelham aos merozoítos de outros coccídeos (Soulsby, 1987).

Os hospedeiros intermediários se infectam pela ingestão de alimentos contaminados com oocistos provenientes do hos-

\footnotetext{
* Médica-veterinária, Ms. E-mail: vaniophillus @yahoo.com

** Prof. DMV/UFRPE Rua Dom Manoel de Medeiros, $s / n$ Dois Irmãos Recife, PE.

*** Bolsista de Desenvolvimento Científico Regional - CNPq - DMV/UFRPE.

**** Mestranda do Programa de Pós-Graduação em Ciência Veterinária - UFRPE.
} 
pedeiro definitivo, que, por sua vez, infecta-se ao ingerir carne crua do hospedeiro intermediário contendo sarcocistos.

Ferreira (1969a) relata que a maior parte da infecção está localizada nos músculos esquelético e cardíaco, podendo atingir língua, laringe, faringe, palatino e esôfago. Ono e Ohsumi (1999) citam que a musculatura esquelética é a parte mais freqüentemente ingerida, onde a prevalência de espécies não específicas são relatadas, mesmo nos poucos trabalhos realizados com número pequeno de amostras. Estes mesmos autores relatam, ainda, que alguns fatores podem estar associados à prevalência da infecção, como o aumento gradual da infecção com o avanço da idade do hospedeiro, variações anatômicas e a localização geográfica do animal. Os Sarcocystis macroscópicos não são patogênicos em geral, enquanto as espécies microscópicas podem causar sérias condições patológicas nos animais (Oryan et al., 1996).

As alterações patológicas nos animais são diversas, mas sua patogenia ainda é incerta. Infecções experimentais vêm demonstrando a patogenicidade do Sarcocystis. Segundo George (1993), as lesões patológicas do Sistema Nervoso Central são similares para todas as espécies de esporozoários, envolvendo meningoencefalomielite granulomatosa, malácia focal, formação de manguitos perivasculares, degeneração neuronal e gliose. As lesões são mais severas no cerebelo e mesencéfalo. Em outras estruturas, as lesões consistem em hemorragias na esclerótica, superfícies serosas e músculos. Os músculos estão mosqueados, apresentando listras claras e escuras alternadas. As alterações macroscópicas podem não estar evidentes em animais com sarcocistose crônica.

Botelho e Ponciano (1996) citam que as espécies de Sarcocystis podem causar doença e até mesmo a morte de animais infectados. Estudos citam que os agentes da sarcocistose são responsáveis por disfunção multissistêmica em animais altamente infectados, porém, na maioria dos animais a doença não é evidenciada, podendo tornar-se clinicamente aparente numa exposição primária do animal. Esta pode variar desde anorexia, diarréia, lentidão e prostração à hiperexcitabilidade e morte. Alguns relatos citam abortos como resultado de Sarcocystis em bovinos. A patogênese do abortamento não está esclarecida, mas de acordo com Miller e Turk (1993) a invasão fetal é rara, e o aborto pode ser conseqüente à febre materna, anemia ou insuficiência placentária. Abo-Shehada (1996) cita que os sinais crônicos, incluindo perda de peso, estão associados com Sarcocystis nos músculos. Ferreira $\left(1969_{\mathrm{a}}\right.$ ) descreve relatos de vários autores nos quais descreveram uma endotoxina típica dos Sarcocystis (sarcocistina), posteriormente denominada sarcosporidiotoxina, sendo ativada após a morte do parasita, destruição ou ruptura do cisto.

\section{Referências}

ABO-SHEHADA, M.N. Age variations in the prevalence of sarcocystosis in sheep and goats from northern and central Jordan. Prev. Vet. Med., v. 27, n. 3/4, p. 135-140, 1996.

BOTELHO, G.G. e PONCIANO, D.S. Sarcocistose aguda experimental em bovino causada por Sarcocystis cruzi (HASSELMAN, 1923) WENYON, 1926 (Apicomplexa, Sarcocystidae): II - Avaliação bioquí-
Como a prevalência das espécies de Sarcocystis não é conhecida e ainda não foi registrada no estado de Pernambuco, a presente investigação teve como objetivo determinar a ocorrência de Sarcocystis spp. em músculo cardiaco de bovino.

\section{Material e métodos}

Vinte e duas amostras de coração bovino foram obtidas em feira livre no município de São Lourenço da Mata (Região Metropolitana do Recife), e encaminhadas ao Laboratório de Patologia Animal do DMV/UFRPE. Incisões foram efetuadas nas paredes das aurículas e ventrículos, além dos septos interauriculares e interventriculares; o material, em seguida, foi fixado em solução de formol a $10 \%$ e transportado ao local do experimento. Procedeu-se, em seguida, a preparação das lâminas para exame histopatológico, utilizando-se técnicas de diafanização, inclusão em parafina, realizando-se cortes histológicos com $5 \mu \mathrm{m}$ de espessura e corados pela hematoxilina-eosina. As lâminas preparadas foram examinadas em microscópio óptico.

\section{Resultados e discussão}

Das amostras analisadas, 100\% mostraram-se infectadas. Os Sarcocystis mostraram-se de forma e tamanho variáveis, com numerosos bradizoítos, separados por septos, de acordo com resultados encontrados por Figueiredo e Lopes (1993) e Pena et al. (1997). Os cistos apresentaram-se extremamente freqüentes nas fibras cardíacas dos bovinos, como descrito por Santos (1986), Ferreira (1969b) e Ono e Ohsumi (1999). Em todas as zonas de cortes no coração, não foram evidenciadas lesões macroscópicas que pudessem levar à suspeita de qualquer alteração da fibra muscular. Não foram também evidenciados macrosarcocystis nestes corações bovinos.

As fibras musculares apresentaram-se integras, similar ao que observou Ferreira (1969a), não sendo verificados processos inflamatórios nos locais infectados. Nestes tecidos, não foram vistas hemorragias, infiltração por células mononucleares ou alterações necróticas provocadas por microsarcocystis como evidenciado por Oryan et al. (1996) ou mesmo esteatose e degeneração de fibra como observado por Ono e Ohsumi (1999).

Merece destaque a evidenciação deste importante parasita, visto ser uma zoonose e ter fácil disseminação entre as diferentes espécies domésticas. Por outro lado, as espécies microscópicas não são detectadas durante a inspeção de rotina nos matadouros, não sendo, portanto, responsabilizados por condenação de carcaças, como afirmado por Oryan et al. (1996).

Este trabalho destaca-se como primeiro registro de Sarcocystis em bovino no estado de Pernambuco.

mica sérica de glicose e frações lipídicas. Rev. Bras. Med. Vet., v. 18, n. 3, p. 127-131. 1996.

FERREIRA, T.M.P Contribuição ao estudo das Sarcosporidioses em Moçambique. II-Sarcosporidiose bovina. Rev. Ciênc. Vet., v. 2, n. 1, p. 139-150, jun. 1969a.

FERREIRA, T.M.P. Sarcosporidiose no aparelho de condução do coração de bovino. Rev. Ciênc. Vet., v.2, n. 1, p. 201-206, jun. 1969b.

FIGUEIREDO P.C e LOPES, C.W.G. The domestic dog (Canis familiaris) 
as final host for S. tenella (RAILLIET, 1886; MOLÉ, 1886) (APICOMPLEXA: SARCOCYSTIDAE) in Brazil. Rev. Bras. Parasitol. Vet., v. 16, n. 3, 1993.

FRASER, C.M. Manual Merck de Veterinária: um manual de diagnóstico, tratamento, prevenção e controle de doenças para o veterinário. São Paulo: Roca, 6. ed., p. 597, 1991.

GEORGE, L.W. Moléstias do Sistema Nervoso Central. In: SMITH, B.P. Tratado de Medicina Interna de Grandes Animais. São Paulo: Manole, v. 2, p. 901-1040, 1993.

HODGSON, D.R. e PARISH, S.M. Miopatias. In: SMITH, B.P. Tratado de Medicina Interna de Grandes Animais. São Paulo: Manole, v. 2, p. 1329-1347, 1993.

MILLER, M.A. e TURK, J.R. Causas infecciosas de infertilidade e de aborto In: SMITH, B.P. Tratado de Medicina Interna de Grandes Animais. São Paulo: Manole, v. 2, p. 1386-1408, 1993.
ONO, M. e OHSUMI, T. Prevalence of Sarcocystisspp cysts in japanese and imported beef (Loin: Musculus longissimus). Parasitol. Internat., v. 48, p. 91-94, 1999.

ORYAN, A.; MOGHADDAR, N. e GAUR, S.N.S. The distribution pattern of Sacocystisspecies, their transmission and pathogenesis in sheep in fars province of iran. Vet. Res. Commun., v. 20, n. 3, p. 243-253, 1996.

PENA, H.F. de J.; OGASSAWARA, S. e SINHORIM, I.L. Freqüência de ocorrência de cistos de Sarcocystis LANKESTER, 1882, em quibe cru comercializado em estabelecimento de cozinha árabe, na cidade de São Paulo. Estudo a fresco e ultraestrutural. Rev. Bras. Parasitol. Vet., v. 6, n. 2. supl., p. 343, ago. 1997.

SANTOS, J.A. Patologia especial dos animais domésticos (mamíferos e aves). 2. ed., Rio de Janeiro: Guanabara Koogan, p. 232, 1986. SOULSBY, E.J.L. Parasitologia y enfermedades parasitarias en los animales domésticos. 7. ed., 1987. 